\title{
Redistribuição e reconhecimento no Prouni: uma análise de justiça social à luz de Nancy Fraser*
}

\author{
Redistribution and recognition in the Prouni Context: \\ an analysis based in the theoretical perspective of Nancy Fraser
}

\author{
Redistribución y reconocimiento en el Contexto de Prouni: \\ un análisis basado en la perspectiva teórica de Nancy Fraser
}

\author{
CRISTINA FIOREZE** \\ JULIO CESAR GODOY BERTOLIN*** \\ BRUNA BORTOLIN****
}

\begin{abstract}
RESUMO - O presente artigo busca analisar em que medida o Programa Universidade para Todos (Prouni), desenvolvido no contexto de instituições de educação superior privadas, possui potencial para gerar justiça social a estudantes de meios populares. Inicialmente, aborda-se o entendimento de justiça social na perspectiva teórica de Nancy Fraser, que integra as reivindicações de redistribuição e de reconhecimento no âmbito da moralidade, tomando como marco referencial a norma universalista da paridade de participação. Na sequência, são apresentados: uma revisão da literatura sobre o programa, bem como sobre experiências de bolsistas, além de entrevistas com estudantes do Prouni no contexto de uma universidade comunitária e sem fins lucrativos. Por fim, a partir do cotejamento entre a concepção de justiça social da autora, de um lado, e as discussões trazidas sobre o Prouni, de outro, argumenta-se que o programa contribui para gerar justiça social entre estudantes provenientes de meios populares.
\end{abstract}

Palavras-chave - Educação superior. Justiça social. Redistribuição e reconhecimento. Prouni.

\begin{abstract}
This paper examines to what extent the University for All Programme - Prouni, developed in private higher education institutions context, has potential to generate social justice for lower background students. Initially, it focuses the understanding of social justice in the theoretical perspective of Nancy Fraser, which incorporates the redistribution and recognition claims in the context of morality, taking the universal principle of parity of participation as reference point. Secondly are presented both literature review about the programme and experiences of students, and interviews with Prouni students in a non-profit community university. Finally, from the mutual comparison between Fraser's social justice conception on the one hand, and discussions presented about Prouni on the other hand, it is argued that the programme helps to generate social justice for lower background students.
\end{abstract}

Keywords - Higher education. Social justice. Redistribution and recognition. Prouni.

RESUMEN - Este trabajo analiza el grado en que el Programa Universidad para Todos (Prouni), desarrollado en el contexto de las instituciones privadas de educación superior, tiene el potencial de generar justicia social para los estudiantes de medios populares. Inicialmente, se acerca a la comprensión de la justicia social en la perspectiva teórica de Nancy Fraser, incorporando las demandas de redistribución y reconocimiento en el contexto de la moral, tomando como punto de referencia la norma universal de la paridad de participación. Después de una revisión de la literatura del programa, así como las experiencias de académicos, así como entrevistas con estudiantes Prouni en el contexto de uma universidad comunitaria y sin fines de lucro se presentan. Por último, a partir del examen entre la concepción de la justicia social por el autor, por un lado, y las discusiones provocadas Prouni por el otro, se argumenta que el programa de ayuda a generar justicia social con estudiantes de medios populares.

Palabras clave - Educación superior. Justicia social. La redistribución y el reconocimiento. Prouni.

* Este artigo é uma versão revisada e significativamente ampliada do trabalho "Educação Superior e Justiça Social: uma avaliação das possibilidades de redistribuição e de reconhecimento pelo Prouni" apresentado no V Seminário Nacional de Sociologia e Política (UFPR, 2014), que foi publicado nos anais e na revista que compilou trabalhos apresentados no evento. $\mathrm{O}$ artigo aqui publicado, entretanto, agrega nova etapa da pesquisa que embasou a publicação acima mencionada. Aqui, as análises são enriquecidas com os resultados de entrevistas realizadas com estudantes e familiares junto a uma universidade sem fins lucrativos do Rio Grande do Sul.

** Mestra em Educação pela Universidade de Passo Fundo (Passo Fundo, RS, Brasil) e professora na Universidade de Passo Fundo (Passo Fundo, RS, Brasil).E-mail: <cristinaf@upf.br>.

*** Doutor em Educação pela Universidade Federal do Rio Grande do Sul (Porto Alegre, RS, Brasil) e professor na Universidade de Passo Fundo (Passo Fundo, RS, Brasil).E-mail:<julio@upf.br>.

**** Especialista em Metodologias de Intervenção com Famílias pela Universidade de Passo Fundo (Passo Fundo, RS, Brasil). E-mail: < brunabortolin@upf.br>. 


\section{INTRODUÇÃO}

A importância da educação superior para o desenvolvimento dos indivíduos e das sociedades é praticamente uma unanimidade mundial. Na literatura especializada são encontrados diversos estudos que associam melhorias das taxas de atendimento com a elevação de indicadores econômicos e sociais. De acordo com a Unesco, "nunca na história foi tão importante investir na educação superior como força maior na construção de uma sociedade inclusiva e de conhecimento diversificado, além de avançar em pesquisa, inovação e criatividade" (2010, p. 1).

Segundo Walter McMahon (2009), os importantes benefícios coletivos da educação superior, incluídos às futuras gerações, podem ser divididos entre os econômicos e os não econômicos. Os benefícios econômicos são principalmente o crescimento da riqueza e a produtividade. Já os não econômicos incluem, dentre outros, o melhor funcionamento do sistema democrático, o compromisso cívico, a coesão social e a geração de novas ideias. Assim, cada vez mais, a educação superior desempenha um papel central tanto no crescimento econômico como na promoção da justiça social dos países.

A ampliação da relevância da educação superior tem levado a uma significativa expansão dos sistemas nacionais em quase todo o mundo. No Brasil, em um período de dez anos, a quantidade de estudantes matriculados dobrou - saindo de 3,5 milhões, em 2002, para mais de 7 milhões em 2012 (INEP, 2013). Entretanto, quando comparado ao contexto internacional, o país ainda apresenta baixos níveis de acesso. Em 2007, enquanto a taxa de escolarização bruta do Brasil era de $30 \%$, a de países vizinhos como Argentina e Uruguai era de aproximadamente 65\% (UNESCO, 2009).

Todavia, juntamente com o desafio da ampliação do acesso, apresenta-se o requisito da ampliação da equidade do sistema de educação superior, ou seja, as oportunidades de acesso devem ser iguais para os mais distintos grupos socioeconômicos. Nos últimos anos, importantes organismos multilaterais e governos de diversos países têm reconhecido o acesso e a equidade como os maiores desafios da educação superior no contexto da globalização.

Nesse sentido, o Brasil tem desenvolvido políticas e implantado programas com o objetivo de expandir com maior equidade o sistema de educação superior. Atualmente, o maior desses programas é o Prouni, uma política de concessão de bolsas de estudos em instituições privadas, com base em critérios como renda familiar e escola frequentada no ensino médio, com reservas especiais para deficientes, indígenas e negros. Apesar de ser alvo de críticas, acusado de constituir-se num reforço do processo de privatização da educação e de proporcionar acesso a ensino sem qualidade ${ }^{1}$, indicadores quantitativos começam a demonstrar o impacto do Prouni e os resultados da política de expansão com equidade. Instituído no ano de 2004, o programa já atendeu mais de 1 milhão de alunos.

Por meio do Prouni e de outros programas, tais como o estabelecimento de cotas nas instituições federais, o acesso de alunos dos meios populares vem crescendo. Em 2002 , apenas $5 \%$ dos estudantes matriculados em cursos de graduação no país pertenciam à classe $\mathrm{D}$, enquanto 'um quarto' pertencia à classe A. Sete anos depois, tal cenário mudou de forma significativa, sendo que a classe D passou a possuir percentualmente o dobro de estudantes do que a classe A (DATA POPULAR, 2010).

Entretanto, analisar as contribuições do Prouni apenas por meio de indicadores das taxas de atendimento é insuficiente. A emissão de juízos sobre o programa não pode basear-se apenas em aspectos quantitativos referentes às bolsas concedidas, visto que questões qualitativas relativas ao desenvolvimento intersubjetivo dos estudantes são fundamentais para uma investigação adequada, especialmente no que tange à contribuição social da educação superior. Dessa forma, com objetivo de avaliar de forma mais ampla o Prouni, desenvolveuse neste artigo uma análise do programa a partir da perspectiva de justiça social proposta por Nancy Fraser (2006a; 2006b; 2007).

Apresenta-se, inicialmente, o "dualismo perspectivo" desenvolvido pela autora, no âmbito do qual justiça social abrange tanto a dimensão da distribuição quanto a do reconhecimento. A seguir, são abordadas experiências dos bolsistas em diferentes instituições, bem como uma pesquisa empírica sobre a percepção dos estudantes de uma universidade sem fins lucrativos são apresentadas. Por fim, a partir do cotejamento entre a concepção de justiça social da autora, de um lado, e as discussões sobre o programa e percepções dos bolsistas, de outro, argumentase que, não obstante algumas situações de preconceito, o Prouni possibilita redistribuição e reconhecimento.

\section{A BIDIMENSIONALIDADE DA JUSTIÇA SOCIAL EM NANCY FRASER}

$\mathrm{O}$ conceito de justiça social surgiu em meados do século XIX, no contexto de questionamento dos trabalhadores sobre as grandes desigualdades do sistema capitalista. Nos dias atuais, dentre os termos relacionados à justiça social, encontram-se igualdade social, igualdade de oportunidades, reconhecimento da diferença e distribuição de renda. Uma das principais pensadoras contemporâneas acerca das concepções de justiça é a norte-americana Nancy Fraser. De acordo com 
essa teórica, no cenário atual há uma reorganização do discurso sobre a justiça social, o qual, historicamente centrado nas lutas por redistribuição, desloca-se para a esfera das lutas por reconhecimento. A pensadora argumenta que os dois tipos de reivindicação encontram-se dissociados e, não raro, apresentam-se como antíteses. Sustenta, porém, que não se trata de escolher entre redistribuição ou reconhecimento ${ }^{2} \mathrm{e}$, apesar das tensões nas relações entre os dois campos, observa que "na atualidade, a justiça exige tanto a redistribuição como o reconhecimento" (tradução dos autores) (2006a, p. 19).

Nancy Fraser se coloca a tarefa de "elaborar um conceito amplo de justiça que consiga acomodar tanto as reivindicações defensáveis de igualdade social quanto as reivindicações defensáveis de reconhecimento da diferença" (2007, p. 103). Visando a enfrentar esse desafio, a autora desenvolve tal conceito nos marcos da moralidade e não da ética. Ou seja, tradicionalmente, a justiça distributiva ${ }^{3}$ é alinhada à moralidade - portanto, ao que é correto - e o reconhecimento, à ética - portanto, à noção de bem. Os teóricos alinhados ao liberalismo ressaltam que o correto se sobrepõe sobre o bem e, para eles, as normas de justiça são universalmente vinculatórias; já os comunitaristas asseveram que "as reivindicações substantivas de valores comunitários culturalmente específicos [estão] acima dos apelos abstratos à Razão ou à Humanidade" (2007, p. 104). Nesse enquadramento tradicional, todavia, é incompatível a integração entre redistribuição e reconhecimento. Fraser desafia tal incompatibilidade, integrando redistribuição e reconhecimento por meio do desenvolvimento de uma noção ampliada de justiça na qual vincula as políticas de reconhecimento ao campo da moralidade, juntamente com as políticas de redistribuição.

A pensadora consegue realizar essa integração na medida em que toma como marco normativo de referência a ideia de paridade de participação. Paridade seria "a condição de ser um igual, de estar a par com os demais, de estar em pé de igualdade". E sua efetivação depende de, pelo menos, duas condições: uma objetiva, que trata da distribuição de recursos materiais "de modo que garanta a independência e a voz de todos os participantes"; e outra intersubjetiva, que se refere ao requerimento de que "os padrões institucionalizados de valor cultural expressem o mesmo respeito a todos os participantes e garantam a igualdade de oportunidades para conquistar a estima social" (tradução dos autores) (2006a, p. 42).

A paridade participativa, para a autora, é uma norma universalista, pois pressupõe o igual valor moral dos seres humanos. Deve ser tomada como critério para discernir as reivindicações justificadas das não justificadas, tanto por reconhecimento quanto por redistribuição.
Independentemente de ser uma questão de distribuição ou reconhecimento, os reivindicantes devem mostrar que os arranjos atuais os impedem de participar em condição de igualdade com os outros na vida social. Os reivindicantes da redistribuição devem mostrar que os arranjos econômicos existentes lhes negam as necessárias condições objetivas para a paridade participativa. Os reivindicantes do reconhecimento devem mostrar que os padrões institucionalizados de valoração cultural lhes negam as condições intersubjetivas necessárias (2007, p. 125).

Assim, a paridade de participação é tomada como norma justificativa, que não pode se constituir por meio de uma decisão de cima. Ela só pode ser determinada dialogicamente e, ainda, tudo o que se postula como tal está sujeito a discussões. A paridade participativa representa, então, "a principal linguagem da razão pública, a linguagem mais adequada para desenvolver uma argumentação política democrática sobre problemas de distribuição e reconhecimento" (tradução dos autores) (2006a, p. 48).

Diante do exposto, verifica-se-se que Fraser apresenta uma proposta de rompimento com o modelo padrão do reconhecimento, qual seja, o da identidade, alinhado à perspectiva comunitarista, no qual o que exige reconhecimento é a identidade cultural de um grupo. Diferentemente, a autora propõe que se trate o reconhecimento a partir de um modelo de status social, situado no campo da moralidade, no qual "o que exige reconhecimento não é a identidade específica de um grupo, mas a condição dos membros do grupo como parceiros integrais na interação social. O não reconhecimento [...] significa subordinação social no sentido de ser privado de participar como um igual na vida social”. Nesse modelo, "o não reconhecimento aparece quando as instituições estruturam a interação de acordo com normas culturais que impedem a paridade de participação" (2007, p. 107). Reconhecimento, no modelo de status, significa superar a subordinação, fazendo do sujeito um membro integral da sociedade, capaz de participar em pé de igualdade com os outros; significa desinstitucionalizar padrões de valoração cultural que impedem a participação como par.

Para Fraser, "é injusto que a alguns indivíduos e grupos se negue o status de interlocutores plenos na interação social como consequência de padrões institucionalizados de valor cultural em cuja elaboração não tenham participado em pé de igualdade e que menosprezam suas diferenças ou as diferenças que os atribuem" (2006a, p. 36). A autora, então, ao operar nos marcos do seu modelo de status, entende que reparar a injustiça - o que certamente requer uma política de reconhecimento - não significa mais uma política de identidade, mas requer, sim, uma política que visa a superar a subordinação, 
fazendo do sujeito falsamente reconhecido um membro integral da sociedade, capaz de participar com os outros membros como igual (2007, p. 108). E para Fraser, o delineamento das políticas de reconhecimento a serem acionadas deve partir de uma compreensão pragmatista das formas de não reconhecimento a serem compensadas. Ou seja, definir em cada caso se a justiça requer o reconhecimento do que é distintivo de alguns indivíduos ou se requer o reconhecimento da nossa humanidade em comum é decorrente de um olhar pragmático. Depende, portanto, da análise da forma de não reconhecimento que se encontra em cada situação (2007, p. 121).

Observa-se, então, que os problemas de reconhecimento são concebidos, no modelo de Fraser, como violação de justiça, o que facilita a articulação das reivindicações de reconhecimento com as de redistribuição, "sem sucumbir à esquizofrenia filosófica" (2007, p. 110). Enquadrar reivindicações de reconhecimento em uma concepção de justiça, alinhando-as à moralidade, possibilita aceitar diferentes concepções de vida boa. O modelo de status, assim, apela "para uma concepção da justiça que pode - e deve - ser aceita por aqueles que tenham divergentes concepções da boa vida" (2007, p. 113). Nessa perspectiva, o não reconhecimento é moralmente inaceitável simplesmente pelo fato de que viola a norma da paridade participativa.

Nessa linha de pensamento, Fraser procura descrever a sociedade contemporânea de modo a apreender, de um lado, a diferenciação de classe social e de status, e de outro, a sua inter-relação. A classe social é entendida como uma ordem objetiva de subordinação, enquanto o status, uma ordem intersubjetiva de subordinação. Então,

dizer que uma sociedade tem uma estrutura de classes é dizer que institucionaliza mecanismos econômicos que negam de forma sistemática a alguns de seus membros os meios e as oportunidades que necessitam para participar na vida social em pé de igualdade com os demais [e] dizer que uma sociedade tem uma hierarquia de status é dizer que institucionaliza padrões de valor cultural que negam por completo a alguns membros o reconhecimento que necessitam para participar plenamente na interação social (tradução dos autores) (2006a, p. 52).

Uma estrutura de classes e/ou uma hierarquia de status é um obstáculo para a paridade participativa, sendo, portanto, uma injustiça.

Diante disso, Fraser propõe o enfoque do "dualismo perspectivo", cujo fundamento é uma concepção bidimensional em que reconhecimento e distribuição são "duas dimensões mutuamente irredutíveis da, e perspectivas sobre, a justiça" (2007, p. 123). Nesse enfoque, o reconhecimento errôneo é analisado, em primeiro lugar, por seu caráter social, ou seja, como uma questão de subordinação de status, buscando-se identificar sua consequência social, qual seja, "a constituição de algumas classes de pessoas como membros não plenos da sociedade de maneira que lhes impeça de participar como iguais" (tradução dos autores) (2006b, p. 166). A má distribuição, por sua vez, é analisada como a institucionalização de mecanismos econômicos que negam a alguns os meios e as oportunidades para participar na vida social em pé de igualdade com os demais. O dualismo perspectivo permite, nas palavras da autora, uma teoria moral socialmente pertinente, a partir da qual se estabelece que tudo o que "mereça o título de injustiça viola um único princípio: o princípio da paridade participativa" (tradução dos autores) (2006b, p. 166).

A autora demonstra que, com o enfoque que propõe, pode-se avaliar a justiça de qualquer prática social questionando: "A prática em questão serve para garantir tanto as condições objetivas como as subjetivas da paridade participativa, ou as debilita?" (tradução dos autores) (2006a, p. 63-64). Em certas situações, remédios para a má distribuição impulsionam problemas de reconhecimento, ou o contrário. $\mathrm{O}$ dualismo perspectivo permite prever e, em alguma medida, evitar, essas dificuldades práticas, pois leva a que se pense de modo integrador na medida em que entende que nenhuma das duas dimensões "pode reparar-se por completo com independência da outra" (tradução dos autores) (2006a, p. 66).

No presente artigo, analisa-se o Prouni à luz do enfoque teórico proposto por Nancy Fraser. Para tanto, na próxima seção, realiza-se uma breve apresentação do programa, contextualizando-o no cenário da educação superior brasileira.

\section{O PROUNi e A PERCEPÇÃo doS ESTUDANTES BOLSISTAS}

O Programa Universidade para Todos (Prouni), criado em 2004, é um programa federal institucionalizado no ano seguinte, por meio da Lei $\mathrm{n}^{\mathrm{o}} 11.096$. Possibilita o acesso a cursos de graduação oferecidos pelas Instituições de Ensino Superior (IESs) privadas (com fins lucrativos e sem fins lucrativos - comunitárias, confessionais e filantrópicas), com bolsas de estudos integrais ou parciais de $50 \%$, a estudantes brasileiros que não possuem diploma de curso superior, pertencentes a famílias com rende bruta mensal per capita limitada e que cursaram o ensino médio sob determinadas condições ${ }^{4}$. Na distribuição das bolsas, as instituições devem reservar percentual para estudantes portadores de deficiência e autodeclarados indígenas e negros, na mesma proporção de cidadãos autodeclarados indígenas, pardos ou pretos, segundo o último censo do IBGE, no respectivo estado. A nota do Exame Nacional 
do Ensino Médio (Enem) é utilizada para a seleção dos estudantes no acesso às bolsas ofertadas ${ }^{5}$.

As instituições que aderem ao programa são obrigadas a disponibilizar bolsas de estudos nas turmas iniciais de todos os cursos e turnos efetivamente instalados, independentemente da procura pelos cursos nos seus próprios processos seletivos. De acordo com a lei, as IESs que aderem ao Prouni, em troca, ficam isentas de um conjunto de impostos, dependendo da categoria administrativa a que pertencem ${ }^{6}$.

Com vistas ao controle social do programa e da distribuição de bolsas foi instituída a Comissão Nacional de Acompanhamento e Controle Social do Prouni (Conap), com funções de supervisão, recebimento de denúncias e de exercício do acompanhamento e controle. Com caráter consultivo, a Conap é formada por representantes de discentes, de docentes, da sociedade civil organizada, de dirigentes de IESs e do Ministério da Educação. No mesmo sentido, no âmbito das instituições estão previstas as Comissões Locais de Acompanhamento e Controle Social do Prouni, a serem instituídas pelas IESs participantes do programa e formadas por representante discente, docente, de dirigente da instituição e da sociedade civil, com as funções de acompanhar o processo de instalação do programa, emitindo relatório de acompanhamento do Prouni nos processos seletivos.

O programa, com aproximadamente dez anos de existência, está citado no novo Plano Nacional de Educação (BRASIL, 2014) como estratégia para ampliar as taxas de matrícula na educação superior para próximos dez anos. Os dados do Prouni permitem observar, entre os anos de 2005 e 2012, uma ampliação em mais de 150\% no número de bolsas ofertadas. Em 2005 foram destinadas 112.275 bolsas, enquanto em 2013 esse número subiu para 252.374. Das bolsas distribuídas no país, no ano de $2013,65 \%$ foram integrais e $35 \%$ parciais. Num sistema de educação superior com aproximadamente 7 milhões de alunos matriculados, o total acumulado de bolsas desde a criação do programa superava o número de 1 milhão e 200 mil bolsas em 2013 (BRASIL, 2014). Com base nesses resultados quantitativos e na medida em que o programa considera critérios de renda, raça e a questão da deficiência de forma combinada com o mérito mensurado pela nota no Enem, pode-se dizer que o Prouni, além de ampliar o acesso por meio de bolsas, coloca-se como ação efetiva no atendimento dos estudantes dos meios populares. Nesse sentido, estudos recentes têm buscado ampliar a análise do programa como política pública por meio da apreensão do processo de desenvolvimento e das vivências intersubjetivas dos bolsistas do Prouni. Tais estudos, em geral, tematizam sobre a percepção dos estudantes no que tange a sua condição de bolsistas, o que é fundamental para a realização de uma avaliação adequada do programa no que diz respeito a sua contribuição para a dimensão social da educação superior.

Em seu artigo de 2007, por exemplo, Bruna C. Anhaia (2012), além de abordar o contexto de surgimento e implantação do Prouni, analisou o processo de redução de pobreza, de empoderamento e também de estigmatização dos bolsistas. Após realizar 18 entrevistas, com estudantes de quatro diferentes instituições da região metropolitana de Porto Alegre, no estado do Rio Grande do Sul, o estudo encontrou importantes evidências de que, se por um lado a situação de pobreza subjetiva dá sinais de diminuição por meio do processo de empoderamento dos bolsistas, por outro, ocorrem resistências ao programa no interior das instituições e animosidade de classes por parte de alguns alunos que pagam com recursos próprios seus estudos.

No sentido de ampliação da autoestima e das perspectivas de futuro, algumas manifestações de estudantes bolsistas apresentadas no artigo são emblemáticas:

[Nos sentimos] orgulhosos, tanto eu quanto a minha família de eu poder estudar... Eu acho que uma das coisas mais legais, assim, é quando tu chega num lugar e perguntam o teu grau de instrução, daí tu fala: 'Superior em andamento'. [...] [E, além disso,] Eu sou mulher, sou jovem, sou negra. Então, quando tu está num espaço - dependendo do espaço que tu está quando tu diz que está fazendo um curso superior, as pessoas já tendem a te tratar de uma outra forma, né? [...] (relato de uma bolsista do curso de Serviço Social apud ANHAIA, 2012, p. 13).

Mudou a perspectiva que eu tenho do futuro. Antes eu pensava em simplesmente me formar no que desse pra já tentar um futuro melhor pra mim. Fui fazer Direito, pensando em me formar, mas não era uma coisa que eu seria feliz. Hoje eu já penso, vou me formar, ter um futuro melhor, ajudar os meus familiares a ter melhores condições, tipo minha irmã, meu irmão. Mas principalmente naquilo que eu gosto (relato de um bolsista do curso de Medicina apud ANHAIA, 2012, p. 13).

Por outro lado, outras entrevistas relatadas no artigo são reveladoras da existência de discriminação com os bolsistas:

Quando eu entrei aqui [em 2005], tinha gente que desmerecia o Enem. Porque eu não entrei pelo vestibular, falavam como se eu tivesse entrado na universidade pela porta de trás. $\mathrm{E}$ isso não tem nada a ver porque a densidade [candidato/vaga] que eu enfrentei pra conseguir a bolsa foi muito maior no Enem do que aquela que eles enfrentaram no vestibular (relato de um bolsista do curso de Medicina apud ANHAIA, 2012, p. 14).

Mais de uma vez eu pensei em desistir. Não porque eu não tenha capacidade, sou muito esforçado $\mathrm{e}$ 
tenho bom desempenho, mas por conta de situações como essa [de discriminação] eu fico me perguntando se aqui é realmente o meu lugar (relato de um bolsista do curso de Direito apud ANHAIA, 2012, p. 16).

Outro artigo, também publicado em 2012, dos autores Maria A. M. Oliveira, Marina L. M. Contarine e Carlos R. J. Cury (2012), analisa a perspectiva de inclusão social e o desempenho dos bolsistas no âmbito da PUC Minas, localizada no estado de Minas Gerais. Por meio de uma pesquisa quanti-qualitativa que utilizou questionários aplicados aos estudantes, os dados coletados demonstraram que a maioria dos bolsistas tem obtido desempenhos positivos, que a evasão é pequena e que o programa tem alcançado êxito como política de inclusão social. Relatos de entrevistas concedidas pelos estudantes bolsistas destacam a importância do programa no sentido de oportunizar o acesso à educação superior, o que pode ser observado na manifestação de uma aluna do curso de Publicidade e Propaganda, para quem "o Enem foi [...] uma porta de entrada, para fazer uma boa faculdade", possibilitando a ela novos sonhos por cursar a educação superior (apud OLIVEIRA, CONTARINE e CURY, 2012, p. 55).

Porém, da mesma forma que na publicação anteriormente relatada, sentimentos de discriminação vividos pelos bolsistas são apresentados:

Senti certa discriminação, pois, em algumas decisões da turma, alguns falavam: 'Vocês não pagam e não têm de reclamar de professor' etc. Mas falei que tinha direito de participar e querer um ensino bom. Fora isso, não tive mais problemas. Os professores são amigos, compreensivos e incentivadores do nosso desempenho (egressa de Serviço Social apud OLIVEIRA, CONTARINE e CURY, 2012, p. 59).

Com o objetivo de aprofundar o olhar para as percepções dos estudantes demonstradas na revisão da literatura apresentada, realizou-se, no ano de 2014, duas entrevistas com bolsistas Prouni de uma universidade comunitária sem fins lucrativos do norte do estado do Rio Grande do Sul: um acadêmico do sexto semestre do curso de Ciências Contábeis e outro acadêmico do quinto semestre do curso de Agronomia. De forma geral, as manifestações de ambos reforçaram as percepções e opiniões presentes nos trabalhos relatados, especialmente acerca do reconhecimento alcançado pelo acesso à educação superior. O bolsista da área de ciências agrárias, por exemplo, manifestou reiteradas vezes que a possibilidade de cursar uma graduação mudou para melhor sua imagem em relação à família e às pessoas em geral:
Em minha opinião, eles [lá] de casa acham que eu vim aqui e estou sabendo mais que eles para aplicar na lavoura. [..] Parece que eu evoluí mais, interajo mais, tenho mais argumentos pra falar, desde [sobre] a lavoura [até] em casa pra trabalhar (acadêmico do curso de Agronomia, 2014).

Sobre perspectivas profissionais, o bolsista demonstrou confiança em relação ao futuro, afirmando que pretende

trabalhar numa multinacional, pra ter contato, conhecimento e mudar a rotina. Não tiro a ideia de trabalhar por conta, é melhor que ser mandado. Ir para [o estado do] Mato Grosso, dar uma conhecida, ficar um tempo lá... Mais pela visão geral que tem nas fazendas de lá, nas plantações e nas culturas diferentes (acadêmico do curso de Agronomia, 2014).

O bolsista da área de ciências sociais aplicadas destacou a questão do reconhecimento das outras pessoas em função de seu acesso a um curso de graduação. Ao manifestar-se sobre o significado de estar na educação superior, disse:

Melhora tua maneira de pensar, você sempre [procura] buscar conhecimentos, e o reconhecimento quando eu falo que estou no curso superior, eles olham de maneira diferente (acadêmico do curso de Ciências Contábeis, 2014).

Ambas as fontes de informações acerca da percepção dos bolsistas, os artigos revisados e as entrevistas realizadas com os bolsistas da instituição comunitária, consubstanciam material de análise do Prouni na perspectiva de sua efetividade como medida voltada à justiça social, essa entendida nos termos de Nancy Fraser. Desse modo, na próxima seção pretende-se desenvolver a problematização do programa com base em categorias analíticas fornecidas por Fraser, o que permite a compreensão do Prouni a partir de tal referencial.

\section{Aplicando a JUSTiÇa SOCIAL de Nancy Fraser ao Prouni}

À luz do dualismo perspectivo de Fraser, pode-se fazer a seguinte questão quando se objetiva a análise do Prouni enquanto medida orientada para a justiça social: o programa garante tanto as condições objetivas como as subjetivas da paridade participativa, ou as debilita?

Nessa direção, cabe perguntar: quais são as condições objetivas, referentes à distribuição de recursos materiais, e as condições intersubjetivas, referentes aos padrões institucionalizados de valor cultural, que o programa pretende reparar? Quais os elementos da estrutura de 
classes e da hierarquia de status que obstaculizam a participação como par, que o Prouni pode superar? E quais os aspectos do programa que permitem apontar para a efetivação de tal superação?

Para responder a essas questões se faz necessário, seguindo a sugestão de Fraser, identificar as dimensões da redistribuição e do reconhecimento presentes no programa, estabelecendo-se como referência a ideia de paridade de participação.

Inicia-se, para tanto, com a dimensão da redistribuição. Nesse sentido, pode-se avaliar que o Prouni, na medida em que estabelece critérios de renda para o ingresso no programa, permite o acesso à educação superior a pessoas de baixa renda, que não teriam condições de acessá-la, ou, então, teriam chances muito reduzidas para tal. Nesse sentido, cabe destacar os dados recentemente divulgados pelo IBGE (2013), demonstrando que, no Brasil, pessoas com formação em nível superior têm rendimento $219,4 \%$ acima das pessoas sem nível superior ${ }^{7}$. Trata-se de uma tendência observada em nível mundial, que demonstra que cursar a educação superior gera expectativas reais de incremento na renda familiar daqueles que a acessaram. Assim, considerando que o ensino superior produz, como efeito, uma ampliação significativa na renda das pessoas, observa-se que o acesso proporcionado pelo Prouni funciona como um instrumento de redistribuição de renda e, portanto, de redução das disparidades sociais.

Outro aspecto que evidencia o caráter redistributivo contido na proposta do Prouni diz respeito à aplicação de verbas públicas (por meio da isenção de impostos) na garantia de vagas na educação superior para pessoas oriundas de famílias de baixa renda. Ou seja, predominantemente, as vagas nas instituições públicas estatais são ocupadas por estudantes oriundos de famílias com maior poder aquisitivo, que puderam pagar por boas escolas e cursos pré-vestibulares. O fato de tais instituições se localizarem em grandes centros, também dificulta o acesso de estudantes de baixa renda provenientes de municípios do interior, que precisam conciliar trabalho e estudo. Diante disso, o Prouni parece gerar um processo corretivo no que tange à distribuição do recurso público na educação superior, contribuindo para a equidade no acesso a esse nível de ensino, uma vez que amplia o ingresso nas instituições que tendencialmente absorvem as populações de baixa renda.

Ainda na dimensão da redistribuição, cabe olhar também para as medidas que visam a garantir, para além do ingresso, a permanência do estudante bolsista na educação superior. Há, nesse sentido, a Bolsa Permanência, do governo federal, que é um benefício financeiro mensal aos estudantes contemplados com bolsa Prouni de 100\%, matriculados em cursos presenciais integrais. Destaca-se, no entanto, que os critérios para recebimento de tal bolsa são bastante restritivos. Também, algumas IESs já estão investindo em programas próprios de permanência de bolsistas, de forma ainda tímida, todavia. As medidas de incentivo financeiro visando à permanência contribuem para que, além da equidade de acesso, o Prouni garanta condições para a equidade de resultados. Esta, segundo Felicetti e Morosini (2009, p. 12), “está ligada a medidas de apoio e acompanhamento para ajudar os alunos que têm maiores dificuldades, principalmente se estas forem de origem socioeconômica".

Diante do exposto, pode-se inferir que o Prouni, ao constituir-se em modalidade de investimento público para a criação de condições de participação da população de baixa renda na educação superior:

a) provoca um processo corretivo no que tange aos gastos públicos com educação superior, direcionando investimentos para as camadas mais empobrecidas da sociedade e contribuindo objetivamente para sua participação nesse nível de ensino;

b) possibilita o ingresso de pessoas de baixa renda à educação superior, que de outra forma não teriam (ou pouco teriam) condições de acessála, reduzindo a reprodução das desigualdades do sistema educacional;

c) amplia, por meio do investimento em programas de permanência, as possibilidades de conclusão de curso para os estudantes bolsistas, contribuindo, por conseguinte, para reduzir o nível de elitização de profissões com reconhecido status social;

d) potencializa o incremento na renda familiar dos bolsistas concluintes, promovendo assim a ampliação dos níveis de mobilidade social no âmbito das camadas mais empobrecidas.

Pode-se afirmar, portanto, que na dimensão da redistribuição o Prouni contribui para que se assegure independência e voz aos sujeitos, ao excluir "formas e níveis de desigualdade material e dependência econômica que impedem a paridade de participação". Assim, evita que se perpetuem determinados arranjos sociais que institucionalizam grandes disparidades de renda e que negam a alguns "os meios e as oportunidades de interagir com outros como parceiros" (FRASER, 2007, p. 119).

Contudo, seguindo a trilha de Nancy Fraser, percebe-se que políticas exclusivamente redistributivas não conseguem responder suficientemente às injustiças sociais próprias da sociedade capitalista contemporânea, as quais apresentam também a esfera do não (ou do falso) reconhecimento. Fraser entende redistribuição e reconhecimento como interligados, porém chama a atenção para a independência que ambas as esferas apresentam entre si. Nesse sentido, cabe então buscar 
uma aproximação com os aspectos de reconhecimento contidos na proposta do Prouni.

Cabe lembrar, inicialmente, que o reconhecimento em Fraser não está relacionado à reparação de identidades lesadas, mas, sim, ao status dos sujeitos como parceiros integrais na interação social. Diz respeito ao direito à participação das pessoas como iguais na vida social, dado o status de ser humano que todos os indivíduos compartilham. $\mathrm{O}$ não reconhecimento significa ser privado de participar como um igual na vida social. Portanto, se a alguém não é reconhecido o direito de participar como igual, cabe a reparação, fazendo-se necessária, então, a superação da subordinação de modo que sejam removidos obstáculos decorrentes de padrões de valor cultural que não permitem a todos a participação plena na interação social.

O Prouni, pode-se dizer, busca reparar algumas modalidades de subordinação decorrentes de padrões de valoração cultural institucionalizados, que levam ao não reconhecimento de determinados grupos sociais como iguais, e que, por isso, têm menores chances de acesso à educação superior. Nessa direção, o programa visa a possibilitar o acesso a esse nível de ensino a pessoas em situação de baixa renda, que estudaram em escolas públicas. As injustiças vivenciadas pelas populações pobres apresentam uma natureza material inquestionável. Contudo, possuem também um viés cultural, ou seja, uma natureza simbólica ${ }^{8}$. Para Fraser, "a construção de um apoio amplo à transformação econômica exige questionar atitudes culturais de desprezo às pessoas pobres e trabalhadoras, como, por exemplo, as ideologias da 'cultura da pobreza', que ressaltam que os pobres têm o que merecem" (tradução dos autores) (2006a, p. 31). O estigma relacionado à condição de pobreza é, então, elemento que coloca os sujeitos em desvantagem no que tange às condições intersubjetivas de participação, ou seja, o modo como as pessoas pobres são notadas no contexto social revela que não estão em pé de igualdade como os demais.

Observa-se, então, que o Prouni busca possibilitar a grupos estigmatizados pela pobreza o acesso a um nível de educação formal (o superior) até então vedado a esses grupos devido ao lugar que, culturalmente, a população pobre ocupa. E esse aspecto vai além do acesso material e econômico, na medida em que o programa amplia as condições de ingresso das parcelas mais pobres da população na educação superior, inclusive em cursos historicamente elitizados. Isto é, percebe-se um importante elemento de superação da hierarquia de status quando o programa oportuniza acesso a cursos de graduação tradicionalmente elitizados. Nestes, as vagas, tanto nas instituições públicas quanto nas privadas, costumam ser ocupadas pelos jovens oriundos de famílias com maior poder aquisitivo, seguindo a lógica da reprodução social. A oferta de bolsas nesses cursos contribui para a reversão de um quadro social caracterizado pelo favorecimento a determinados grupos sociais nas carreiras mais reconhecidas e rentáveis. Portanto, colabora para viabilizar, no espaço da educação superior - e, consequentemente, no mundo do trabalho -, a participação em condição de igualdade da população estigmatizada culturalmente pela pobreza.

Outro viés analítico na dimensão do reconhecimento envolve a compreensão de que, para além da questão do estigma social gerado pelo desprestígio da condição de pobreza, o Prouni opera no sentido da garantia de cotas para pessoas com deficiência, negros e indígenas (de acordo com o percentual de cidadãos assim declarados no último censo, em âmbito estadual), dentro dos critérios de renda estabelecidos. Nesse sentido, o programa se posiciona de modo a amplificar as condições de paridade de participação de grupos sociais historicamente subordinados em decorrência de processos de discriminação racial e social.

Sobre tal aspecto importa destacar que, no Brasil, as desigualdades de renda e a discriminação racial andam, pode-se dizer, de mãos dadas. Ou seja, há a coincidência da participação de populações negras e indígenas vivendo em realidades de pobreza e de baixo prestígio social. Nesse cenário, faz sentido a adoção de políticas que combinem critérios de renda com critérios raciais, como é o caso do Prouni, o que significa conciliar redistribuição com reconhecimento.

Mais um aspecto do reconhecimento contido na implementação do Prouni trata da compreensão de que o mesmo estabelece um processo republicano, com critérios públicos e objetivos para a concessão de bolsas de estudos. Ou seja, muitas IESs, em especial aquelas caracterizadas como filantrópicas, já trabalhavam com a concessão de bolsas de estudos antes mesmo da adesão ao programa. Operavam, contudo, com critérios definidos internamente e pouco claros, que abriam margem para situações de favorecimento e/ou exclusão, reforçando a lógica da reprodução de valores culturais geradores de subordinação de status. Na contramão dessa tendência, com a instalação do programa nessas instituições (e nas demais IESs de direito privado que assinaram o termo de adesão), o acesso às bolsas passou a ser dar por meio de critérios objetivamente estabelecidos e por um processo impessoal, reforçando a lógica republicana do acesso à bolsa como direito e não como favor.

Ainda analisando a perspectiva do reconhecimento, com base nos relatos de bolsistas transcritos na seção anterior, observa-se o empoderamento decorrente do acesso à educação superior. Tal empoderamento pode ser compreendido como resultante da remoção de elementos 
que compõem a subordinação de status e, assim, como uma condição intersubjetiva da paridade de participação.

Ao mesmo tempo, todavia, o preconceito e a discriminação, vivenciados por estudantes bolsistas e também observados nas falas transcritas, são um dado da realidade que permite supor que, talvez, as condições de participação efetiva como igual, nos termos de Fraser, ainda estejam em processo de construção nas instituições que acolhem os beneficiários do programa. Ou seja, a superação da subordinação de status não é dada como decorrência imediata da garantia das condições objetivas e materiais viabilizadas pelo ingresso na educação superior, apresentando-se como algo mais complexo a se alcançar. Constata-se, então, que reconhecimento é, ainda, uma caminhada em processo.

Isto posto, é plausível afirmar que o Prouni, na medida em que trabalha com critérios públicos para a concessão de bolsas de estudos em IESs de direito privado, reconhecendo a humanidade em comum dos distintos grupos sociais e viabilizando o acesso à educação superior (inclusive aos cursos que correspondem às carreiras mais prestigiosas) a grupos sociais estigmatizados pela pobreza, combinando o fator racial e a questão da deficiência com a renda:

a) estabelece critérios universais e objetivos para a concessão das bolsas de estudos, impessoalizando o processo e favorecendo que o acesso seja construído na forma de direito e não como benesse ou favor;

b) contribui para superar a hierarquia de status e a subordinação cultural e simbólica a que estão submetidos os grupos sociais empobrecidos, colaborando para que se tornem parceiros integrais na vida social;

c) favorece a superação da subordinação de status relacionada à exclusão racial, fortemente ligada à questão econômica, bem como a subordinação de status decorrente das injustiças vivenciadas pelas pessoas com deficiência;

d) consubstancia, com os estudantes bolsistas, um processo de empoderamento, o qual decorre de acesso à educação superior por jovens oriundos de contextos sociais suscetíveis a discriminação e preconceito;

e) evidencia, por meio das situações de preconceito vivenciadas por bolsistas, que o processo de inclusão gerado pelo programa produz, também, desconforto naqueles que detinham para si (e seus grupos) o acesso à educação superior como elemento de distinção social e, portanto, de manutenção de uma ordem hierárquica, demonstrando que a dimensão do reconhecimento pela via do Prouni é, ainda, um processo em construção.
Finalmente, o aspecto que chama a atenção na proposta do Prouni e que merece destaque pelo potencial que representa diz respeito às Comissões (Nacional e Locais) de Acompanhamento e Controle Social do programa. São espaços de representatividade dos estudantes bolsistas e dos demais grupos implicados no processo, em que existe a possibilidade da participação, da fala, do diálogo, da negociação coletiva. Ou seja, trata-se de lugares de discussão acerca das percepções dos diretamente envolvidos no Prouni sobre padrões institucionalizados de valor cultural, bem como sobre proposições para o programa, no sentido da construção da paridade participativa. Analisando a parir da ótica de Fraser, percebe-se nessas comissões, em especial as locais, potência para a constituição de espaços dialógicos de discussão e negociação, em que a paridade de participação pode acontecer como "a linguagem mais adequada para desenvolver uma argumentação política democrática sobre problemas de distribuição e reconhecimento" (FRASER, 2006a, p. 48).

\section{CONSIDERAÇõeS FINAIS}

Em face do contexto de crescimento da relevância da educação superior na sociedade do conhecimento, o acesso a esse nível de ensino passa a ser considerado importante fator de geração de justiça social na sociedade contemporânea. Diante disso, propõe-se a discutir e avaliar o Prouni a partir da teoria bidimensional de justiça proposta por Nancy Fraser, com o objetivo de analisar o potencial do programa para gerar justiça social entre os estudantes dos meios populares.

Para Fraser, a justiça social envolve tanto redistribuição como reconhecimento, que se inter-relacionam, apesar de manterem certa independência entre si. O centro normativo dessa concepção bidimensional da justiça encontra-se na ideia de paridade de participação, que diz respeito ao direito de todos de participarem como iguais na interação social. A concepção de justiça da autora está situada, portanto, na esteira liberal da moralidade. Esse enfoque, ao possibilitar que se pense de modo integrador, permite analisar se uma prática garante tanto as condições objetivas (ligadas à má distribuição) quanto as intersubjetivas (ligadas ao não reconhecimento) da paridade de participação. Ancorado nesse enfoque, o artigo buscou analisar de forma mais ampla o Prouni.

A análise desenvolvida permitiu identificar no programa tanto elementos de redistribuição quanto elementos de reconhecimento. Quanto à dimensão redistributiva, evidencia-se que a proposta propicia um processo corretivo no que tange ao investimento de recursos públicos na educação superior, uma vez que 
o Prouni viabiliza o acesso à graduação para jovens oriundos de meios populares, pertencentes a famílias de baixa renda. Assim, o programa contribui para a redução das disparidades econômicas, ampliando as expectativas futuras de incremento na renda dos bolsistas, o que se dá em razão da possibilidade de formação no nível superior de ensino. Então, pode-se dizer que o Prouni contribui para que se assegure independência e voz aos sujeitos, superando obstáculos materiais e econômicos que impedem a participação de alguns como parceiros plenos da sociedade.

De modo complementar, a dimensão do reconhecimento pode ser identificada quando o Prouni contribui na superação do processo de reprodução de uma hierarquia estabelecida entre elites e classes populares, onde o acesso à educação superior, em especial em cursos mais tradicionais, é tido como um bem exclusivo dos grupos sociais dominantes. Da mesma forma, o programa estabelece critérios universais para a concessão das bolsas de estudos, impessoalizando o processo e possibilitando que o acesso seja construído na forma de direito e não como benesse ou favor. Observa-se, ainda, a dimensão do reconhecimento quando o programa favorece a superação da subordinação de status relacionada à exclusão racial, fortemente ligada à questão econômica, bem como a subordinação de status decorrente das injustiças vivenciadas pelas pessoas com deficiência.

Restam, entretanto, aspectos contraditórios no que tange à construção de um processo de reconhecimento a partir do Prouni. De um lado, percebe-se o empoderamento gerado pelo acesso ao programa. Em contraposição, observa-se o preconceito vivenciado por aqueles que adentraram a educação superior por meio do Prouni. Os dois aspectos coexistem, demonstrando que se trata de um processo instituinte que, por sua própria natureza, ao tensionar hierarquias historicamente arraigadas na estrutura social do país, produz contradições.

Diante do exposto, na tentativa de responder à questão inicialmente colocada - o Prouni garante tanto as condições objetivas como as intersubjetivas da paridade participativa, ou as debilita? -, a resposta, apesar de complexa, tende a ser positiva. Em que pese a compreensão de que a experiência do preconceito pela qual os bolsistas estão sujeitos é aspecto a ser superado, pode-se afirmar que o Prouni é uma experiência que mostra correspondência com a tese de Fraser de conciliação entre reconhecimento e redistribuição.

\section{REFERÊNCIAS}

ANHAIA, Bruna Cruz. Políticas públicas e sociais para a equidade: um estudo sobre o Programa Universidade para Todos. Cadernos Gestão Pública e Cidadania, São Paulo, v. 17, n. 60, jan./jun. 2012.
BRASIL. Lei no 11.096, de 13 de janeiro de 2005. Institui o Programa Universidade para Todos - PROUNI, regula a atuação de entidades beneficentes de assistência social no ensino superior, altera a Lei no 10.891 , de 9 de julho de 2004, e dá outras providências. Brasília, DF, 2005.

BRASIL. Lei no 13.005, de 25 de junho de 2014. Plano Nacional de Educação. Diário Oficial da União: seção 1, Brasília, DF, edição extra, p. 1, jun. 2014.

CARVALHO, Cristina Almeida de. Uma análise crítica do financiamento do PROUNI: instrumento de estímulo à iniciativa privada e/ou democratização do acesso à educação superior? In: REUNIÃO ANUAL DA ASSOCIAÇÃO NACIONAL DE PÓS-GRADUAÇÃO E PESQUISA EM EDUCAÇÃO, 34., 2011, Natal. Anais... Natal, 2011.

DATA POPULAR. Classes sociais e ensino superior. São Paulo: Instituto Data Popular, 2010.

FLEISCHACKER, Samuel. A short history of distributive justice. Cambridge, Massachusetts: Harvard University Press, 2009.

FRASER, Nancy. Uma deformación que hace imposible el reconocimiento: réplica a Axel Honneth. In: FRASER, Nancy; HONNETH, Axel. In: ¿Redistribución o reconocimiento?: un debate político-filosófico. Madrid: Morata, 2006a. p. 17-88.

FRASER, Nancy. La justicia social em la era de la política de la identidad: Redistribución, reconocimiento y participación. In: FRASER, Nancy; HONNETH, Axel. In: ¿Redistribución o reconocimiento?: un debate político-filosófico. Madrid: Morata, 2006b. p. 149-175.

FRASER, Nancy. Reconhecimento sem ética? Lua Nova, São Paulo, n. 70, p. 101-138, 2007.

INSTITUTO NACIONAL DE ESTUDOS E PESQUISAS EDUCACIONAIS ANÍSIO TEIXEIRA (INEP). Disponível em: <http://www.inep.gov.br>. Acesso em: 04 jul. 2013.

MCMAHON, Walter W. Higher learning, great good: the private and public benefices of higher education. Baltimore: JHU Press, 2009.

FELICETTI, Vera Lucia; MOROSINI, Marília Costa. Equidade e iniquidade no ensino superior: uma reflexão. Ensaio: avaliação e políticas púbicas em educação, Rio de Janeiro, v. 17, n. 62, p. 9-24, jan./mar. 2009.

LIMA, Kátia Regina de Souza. O Banco Mundial e a educação superior brasileira na primeira década do novo século. Revista Katálysis, Florianópolis, v. 14, n. 1 p. 86-94, jan./jun. 2011.

OLIVEIRA, Maria Auxiladora Monteiro; CONTARINE, Marina Lindaura Maranha; CURY, Carlos Roberto Jamil. Prouni: análise de uma política pública no âmbito da PUC Minas. RBPAE. v. 28, n. 1, p. 48-67, jan./abr. 2012.

PEIXOTO, Maria do Carmo de Lacerda. Políticas para a democratização do acesso e a inclusão social na educação superior do Brasil. In: PAULA, Maria de Fátima Costa de; LAMARRA, Norberto Fernández (Org.). Reformas e democratização da educação superior no Brasil e na América Latina. Aparecida, SP: Ideias e Letras, 2011.

ORGANISATION ECONOMIC CO-OPERATION AND DEVELOPMENT (OECD). Disponível em: $<$ http://stats.oecd. org/index.aspx?queryid=23113>. Acesso em: 13 set. 2011. 
UNITED NATIONS EDUCATIONAL, SCIENTIFIC AND CULTURAL ORGANIZATION (UNESCO). Trends in Global Higher Education: Tracking an Academic Revolution. A Report Prepared for the UNESCO 2009 World Conference on Higher Education. Paris: Unesco, 2009.

UNITED NATIONS EDUCATIONAL, SCIENTIFIC AND CULTURAL ORGANIZATION (UNESCO). 2009 World Conference on Higher Education: The New Dynamics of Higher Education and Research for Societal Change and Development. Communique. Paris: Unesco, 2010.

\section{Notas}

1 As principais críticas ao Prouni argumentam que a medida implica renúncia fiscal por parte das IESs privadas e, nesse sentido, questionam sobre sua atuação em benefício da recuperação financeira de instituições particulares, em detrimento da ampliação do setor público estatal (PEIXOTO, 2011; LIMA, 2011). Outra crítica levantada trata da baixa qualidade de cursos oferecidos por instituições privadas, especialmente aquelas de caráter mercantil, e que, então, a ampliação das taxas de acesso por meio dessas instituições, que recebem os bolsistas Prouni, reforçaria o problema da baixa qualidade da educação superior.

2 Na obra Scales of Justice (publicada em 2009 pela Columbia University Press), posterior às publicações utilizadas como referencial nesse artigo, a autora Nancy Fraser agregou aos problemas de redistribuição da riqueza no plano econômico e de reconhecimento no âmbito dos direitos individuais e coletivos o problema da representação no âmbito político.
3 Segundo Samuel Fleischacker (2009), o entendimento moderno de justiça distributiva está ligado à ideia de se garantir a todas as pessoas um nível mínimo adequado de meios materiais.

4 Para concorrer às bolsas integrais, o candidato deve ter renda familiar de até um salário mínimo e meio por pessoa e, para as bolsas parciais, a renda familiar deve ser de até três salários mínimos por pessoa. Além disso, o candidato deve satisfazer a pelo menos uma das condições a seguir: (i) ter cursado o ensino médio completo em escola da rede pública; (ii) ter cursado o ensino médio completo em escola da rede privada, na condição de bolsista integral da própria escola; (iii) ter cursado o ensino médio parcialmente em escola da rede pública e parcialmente em escola da rede privada, na condição de bolsista integral da própria escola privada; (iv) ser pessoa com deficiência; (iv) ser professor da rede pública de ensino, no efetivo exercício do magistério da educação básica e integrando o quadro de pessoal permanente da instituição pública e concorrer a bolsas exclusivamente nos cursos com grau de licenciatura. Nesse último caso, não há requisitos de renda (BRASIL, 2005).

5 Para o ano de 2014, pôde se inscrever o estudante que participou do Enem de 2013 , desde que tivesse obtido no mínimo 450 pontos na média das notas do exame e nota acima de zero na redação.

6 Com a adesão ao Prouni, a isenção tributária das IESs privadas ampliou em $33,7 \%$, para as com fins lucrativos, em 19,4\%, para as sem fins lucrativos e, em 10,4\%, nas filantrópicas. No período 2005-2009, estimase que a renúncia fiscal com o Prouni tenha sido de aproximadamente R\$ 1,3 bilhão (CARVALHO, 2011).

7 Notícia divulgada no site do IBGE, em 24 de maio de 2013.

8 Segundo Fraser, "os danos de status que se originaram como subprodutos da estrutura econômica podem ter desenvolvido desde então uma vida própria" (tradução dos autores) (2006a, p. 31).

Artigo recebido em dezembro 2014.

Aprovado em maio 2015. 